\title{
O QUE AS PROFESSORAS DA EDUCAÇÃO INFANTIL ENSINAM SOBRE NÚMEROS? ${ }^{1}$
}

\author{
Klinger Teodoro Ciríaco ${ }^{2}$ \\ https://orcid.org/0000-0003-1694-851X \\ Maiara da Rocha Silva ${ }^{3}$ \\ https://orcid.org/0000-0002-9584-9837
}

RESUMO: Compreender aspectos abordados e procedimentos adotados para o ensino de números em turmas de pré-escola constituiu-se objetivo central desta investigação. A abordagem metodológica adotada se inscreve no campo da pesquisa qualitativa em educação e a coleta das informações pertinentes aos objetivos do trabalho de campo foi possível a partir da técnica de observação direta das aulas e de uma entrevista semiestruturada desenvolvida com as colaboradoras. Já o enquadramento teórico, possibilitado pelas reflexões e diálogos com autores que discutem a temática de ensino de números, trouxe uma compreensão da relevância de se trabalhar o campo numérico, que envolve uma prática pedagógica para além da contagem e das operações aritméticas iniciais. No caso analisado, os dados revelaram que a abordagem conceitual desta área do conhecimento matemático ainda se restringe ao aspecto cardinal do número, à sequência numérica, contagem oral de meninos e meninas, introdução à adição quando do momento de "juntar" parcelas.

PALAVRAS-CHAVE: Matemática na Educação Infantil, Prática Pedagógica, Ensino de número

\section{WHAT DO CHILD EDUCATION TEACHERS TEACH ABOUT NUMBERS?}

ABSTRACT: The objective of this research is understand aspects covered and procedures adopted for teaching numbers in preschool classes. The qualitative approach in education was adopted and the information pertinent to the objectives of the field work was possible through the technique of direct observation of the classes and a semi-

\footnotetext{
${ }^{1}$ Artigo fruto de uma pesquisa vinculada ao "Grupo de Estudos e Pesquisas sobre Início da Docência e Ensino de Matemática" - GEPIDEM/CNPq - da Fundação Universidade Federal de Mato Grosso do Sul UFMS, Campus Naviraí.

2 Pós-Doutor em Psicologia da Educação Matemática pela UNESP-Bauru; Professor Adjunto do Departamento de Teorias e Práticas Pedagógicas - DTPP - da Universidade Federal de São Carlos - UFSCar, São Carlos-SP, Brasil.ciriacoklinger@gmail.com

${ }^{3}$ Licenciada em Pedagogia pela UFMS - Campus Naviraí; Professora de Educação Infantil da Rede Municipal de Naviraí-MS, Brasil. E-mail: maah.rs07@hotmail.com
} 
structured interview developed with the collaborators. The theory used, coupled with the reflections and dialogues with authors who discuss the theme of number teaching, brought an understanding of the relevance of working the numerical field, which involves a pedagogical practice beyond counting and initial arithmetic operations. The data analyzed show that the conceptual approach of this area of mathematical knowledge is still restricted to the cardinal aspect of the number, to the numerical sequence, oral counting of boys and girls, introduction to addition when the moment of "joining" plots.

KEYWORDS: Mathematics in Early Childhood Education, Pedagogical Practice, Number teaching

\section{¿QUÉ ENSEÑAN LOS PROFESORES DE EDUCACIÓN INFANTIL SOBRE LOS NÚMEROS?}

RESUMEN: La comprensión de los aspectos abordados y los procedimientos adoptados para enseñar números en las clases de preescolar fue el objetivo principal de esta investigación. El enfoque metodológico adoptado se encuentra en el campo de la investigación cualitativa en educación y la recopilación de información pertinente a los objetivos del trabajo de campo fue posible a partir de la técnica de observación directa de las clases y una entrevista semiestructurada desarrollada con los colaboradores. El marco teórico, hecho posible por reflexiones y diálogos con autores que discuten el tema de la enseñanza de números, trajo una comprensión de la relevancia de trabajar el campo numérico, que implica una práctica pedagógica más allá del conteo y las operaciones aritméticas iniciales. Los datos analizados revelan que el enfoque conceptual de esta área del conocimiento matemático todavía está restringido al aspecto cardinal del número, secuencia numérica, conteo oral de niños y niñas, introducción a la suma cuando es hora de "unir" tramas.

PALABRAS CLAVE: Matemáticas en Educación Infantil, Práctica pedagógica, Enseñanza de números

\section{Introdução}

Relatamos processos de observação, inicialmente decorrentes de práticas de estágio obrigatório desenvolvidas no ambiente de turmas de creches e jardim de infância, realizadas durante o ano letivo de 2015, como também um estudo exploratório com duas professoras atuantes na pré-escola no ano de 2016.

A justificativa encontra respaldo no fato de que, cotidianamente, 
observou-se pela experiência do estágio, que as docentes exploravam aspectos quantitativos na rotina diária com as crianças, contudo, verificamos outras possibilidades de apresentação do número que não foram abordadas com as turmas. Nesse sentido, compreendemos ser preciso investigar quais as dificuldades na organização do trabalho com esse campo matemático para apresentação dos diferentes aspectos numéricos desde as primeiras vivências infantis.

A relevância do trabalho parte ainda em tentar responder algumas perguntas sobre qual a forma mais adequada para se inserir o número com a criança pequena, bem como quais os métodos que o professor pode recorrer para a realização desta tarefa.

Os dados coletados envolveram a confluência das observações numa perspectiva geral para que pudéssemos identificar o que as docentes abordam em relação à temática "números". Posteriormente, como forma de complementação das informações obtidas nas turmas, via acompanhamento direto das observações, desenvolveu-se um roteiro de entrevista semiestruturada que possibilitou perceber e relacionar questões para além do observável.

\section{Algumas recomendações para o ensino de números às crianças pequenas}

Em nosso convívio, o número está, constantemente, presente e exercendo várias funções. Segundo Lorenzato (2008, p. 32), o número precisa ser abordado, desde a Educação Infantil, a partir de diferentes vertentes: "[...] como localizador, identificador, ordenador, quantificador, cardinalidade, ordinalidade, para cálculos e medidas". Nesse sentido, qualquer que seja o tipo de relação numérica, ela sempre pressupõe noções elementares, tais como: "[...] um depois de outro, este se relaciona com aquele, isto contém aquilo, eles são parecidos, é a mesma coisa" (LORENZATO, 2008, p.32).

Sendo assim, é notório que as crianças desde o nascimento estão permeadas por esses conhecimentos matemáticos e variadas são as situações nas quais os números se destacam e apresentam-se no cotidiano, o que permite o desenvolvimento de uma série de situações envolvendo essa área do conhecimento como, por exemplo, relações entre quantidades, número da casa, do sapato, de telefones, em placas de carros, entre outros.

A Matemática passa a fazer parte do universo infantil desde a mais tenra idade, assim noções sobre espaço e medidas também permeiam a vida das crianças e passam a colocá-las em momentos oportunos para ampliação de sua aprendizagem. Essa vivência, inicialmente prática, leva a criação de estratégias para resolver problemas diários, utilizando recursos próprios, ques- 
tões essas que podem favorecer a elaboração de conhecimentos matemáticos (BRASIL, 1998).

Tendo em vista as possibilidades de trabalho com o campo matemático, sintetizamos no quadro 1 , questões a serem exploradas com a criança pequena a partir de uma articulação entre os eixos do Referencial Curricular Nacional para a Educação Infantil - RCNEI - (BRASIL, 1998) e as características declaradas por Lorenzato (2008) como sendo importantes para a construção do conceito de número na perspectiva do uso social.

Quadro 1: Descrição do bloco de conteúdos "Números e sistema de numeração" pelo RCNEI e possibilidades de trabalho mencionadas por Lorenzato (2008).

\begin{tabular}{|c|c|}
\hline \multicolumn{2}{|c|}{ ENSINO DE NÚMEROS } \\
\hline RCNEI (1998) & LORENZATO (2008) \\
\hline \multirow{4}{*}{$\begin{array}{l}\text { - Utilização da contagem oral nas } \\
\text { brincadeiras e em situações nas } \\
\text { quais as crianças reconheçam } \\
\text { sua necessidade. } \\
\text { - Utilização de noções simples } \\
\text { de cálculo mental como } \\
\text { ferramenta para resolver } \\
\text { problemas. } \\
\text { - Comunicação de quantidades, } \\
\text { utilizando a linguagem oral, } \\
\text { a notação numérica e/ou } \\
\text { registros não convencionais. }\end{array}$} & $\begin{array}{l}\text { Localizador: Pode ser encontrado } \\
\text { designando endereço, latitude, } \\
\text { distância; }\end{array}$ \\
\hline & $\begin{array}{l}\text { Identificador: Está nas datas, } \\
\text { nos telefones, nas páginas, nos } \\
\text { automóveis, nas camisetas dos } \\
\text { jogadores; }\end{array}$ \\
\hline & $\begin{array}{l}\text { Ordenador: indica o andar do } \\
\text { apartamento, a posição obtida numa } \\
\text { competição; }\end{array}$ \\
\hline & $\begin{array}{l}\text { Quantificador: Indica velocidade, } \\
\text { consumo, remuneração, altura; }\end{array}$ \\
\hline
\end{tabular}


- Identificação da posição de um objeto ou número numa série, explicitando a noção de sucessor e antecessor.

- Identificação de números nos diferentes contextos em que se encontram.

- Comparação de escritas numéricas, identificando algumas regularidades.

\begin{tabular}{|c|}
\hline $\begin{array}{l}\text { com } \\
\text { otal, } \\
\text { ade. } \\
43\end{array}$ \\
\hline $\begin{array}{l}\text { Número como final de contagem, } \\
\text { em que é forte a ordinalidade. } \\
\text { Por exemplo: ele é o } 4^{\circ} \text { filho; }\end{array}$ \\
\hline $\begin{array}{l}\text { Número (cálculo) como resultado } \\
\text { de operações; }\end{array}$ \\
\hline
\end{tabular}

Número (numerosidade) com significado de quantidade total, em que é forte a cardinalidade. Por exemplo: na sala estudam 43

Número como final de contagem, em que é forte a ordinalidade. Por exemplo: ele é o $4^{\circ}$ filho;

Número (cálculo) como resultado de operações;

resultado de mensuração.

Fonte: Os autores, 2017.

Na perspectiva de trabalho recomendada pelo quadro que elaboramos, o desenvolvimento dos conceitos está fortemente atrelado às experiências informais e pode ser representado por trajetórias de aprendizado que ressaltam o modo de competências específicas dos sujeitos. Com isso, caberia então ao professor oportunizar/favorecer experiências matemáticas adequadas para a faixa etária que atua, bem como que enriqueçam o vocabulário matemático dos pequenos. No caso da Educação Infantil, a curiosidade natural e precoce das crianças pode ser uma forte aliada do docente em suas explorações com as noções matemáticas.

Contudo, para que a abordagem de números ocorra de forma a favorecer a aprendizagem significativa na infância, é preciso desmitificar algumas crenças que parecem residir no cenário do ideário pedagógico dos professores como, por exemplo, a ideia inadequada de que as crianças aprendem por repetição, memorização e associação, característica essa muito comum de se observar em atividades da rotina diária da Educação Infantil, como é o caso da leitura dos numerais em turmas de pré-escola.

Como podemos perceber, em uma apreciação crítica na leitura de documentos orientadores da prática em vigência no período da investigação que realizamos ${ }^{4}$, o RCNEI (BRASIL, 1998) destaca que com a ampliação dos estudos sobre o desenvolvimento infantil e pesquisas realizadas no campo da

\footnotetext{
${ }^{4}$ A investigação descrita neste paper fora desenvolvida entre os anos de 2015 e 2006. Por essa razão, não incorporamos, na discussão, menção aos dizeres da Base Nacional Comum Curricular - BNCC - (BRASIL, 2017), a qual figura objeto de inúmeras críticas quanto ao processo de sua elaboração, como ainda a fundamentação posta em suas orientações.
} 
própria Educação Matemática essa concepção de aprendizagem, e as utilizações desses métodos, estão ultrapassados. Está claro que dessa forma as crianças não aprendem, elas apenas decoram para cada momento.

Dadas as reflexões acima, uma proposta de trabalho mais adequada para a abordagem de números precisa ser aquela que leva em consideração não só os aspectos ordinais e de inclusão hierárquica, como também "[...] primeiramente a fazer correspondência, comparações, classificações etc.; depois, denominar o processo de conservações de quantidades; em seguida a contagem; e, finalmente, as operações [...]" (LORENZATO, 2008, p. 32).

Por meio de estudos feitos pelo Lorenzato (2008), podemos perceber que as primeiras contribuições negativas para as crianças da Educação Infantil partem, algumas vezes, dos próprios professores, pois os mesmos não incluem no processo de exploração matemática inúmeras atividades por julgá-las simples e, portanto, desnecessárias ou inúteis para a aprendizagem, e também os familiares que cobram o ensino dos numerais ${ }^{5}$ e até mesmo de algumas "continhas".

Sendo assim, o espaço da pré-escola pode proporcionar e mediar experiências que envolvam a temática dos números para além do observável, ou seja, as atividades numéricas propostas, quando desenvolvidas sob diferentes enfoques e sentidos do número, podem contribuir para que as crianças adquiram novos saberes, pois é nesta etapa educacional que elas constroem seus conhecimentos e habilidades, a partir de relações mentais próprias das noções lógico-matemáticas.

Moretti e Souza (2015, p. 58) contribuem com a discussão ao afirmarem que explorar "[...] todos esses conhecimentos ao aluno da educação infantil servirá como um degrau natural para a aprendizagem, e é importante que o professor possibilite situações nas quais as crianças possam relacionar ativamente com o conceito matemático".

A partir das contribuições de trabalhos desenvolvidos por experiências piagetianas, podemos conceituar número como sendo uma relação criada mentalmente por cada indivíduo (KAMII, 2012). Tal entendimento levanta a necessidade de propor tarefas investigativas no cotidiano das crianças que as façam pensar para além do conhecimento físico e social, chegando assim a elaboração do conhecimento lógico-matemático.

\footnotetext{
${ }^{5}$ Referimo-nos ao termo "numeral" como sendo o algarismo (registro escrito da grafia numérica. Ex: 1, 2, 3...). ${ }^{6}$ Nas quais as relações de construção do conceito de número parecem mais explícitas, pois "número" refere-se ao processo de quantificação [relação mental feita pelo indivíduo] (quanto o numeral "1" representa, em termos de elementos, e qual valor poderemos obter ao adicionarmos " $1+3$ ", por exemplo).
} 
O conhecimento lógico-matemático consiste na coordenação de relações. Por exemplo, ao coordenar as relações de igual, diferente e mais, a criança se torna apta a deduzir que há mais contas do mundo que contas vermelhas e que há mais animais do que vacas. Da mesma forma é coordenando a relação entre "dois" e "dois" que ela deduz que $2+2=4$ e que $2 \times 2=4$ (KAMII, 2012, p. 19).

Uma proposta de trabalho com números, desde os primeiros momentos da criança com esse campo, precisa considerar contextos específicos do fazer matemático de suas ações cotidianas em uma perspectiva reflexiva acerca deles, ou seja, é necessário a criação de um ambiente, organizado pedagogicamente, que favoreça descobertas ao mesmo tempo em que leva a criança a tecer relações mentais organizando seu pensamento numérico.

O papel do professor, neste contexto, não consistirá, necessariamente, em ensinar, mas sim, contribuir por meio das situações propostas para que a turma construa o conceito de número, uma vez que este é definido como sendo a relação mental feita pelo indivíduo. Nesta concepção, torna-se basilar que o docente conheça e proponha uma abordagem que enfoque processos e situações-problemas para além da contagem oral, escrita e leitura de numerais, como também o trabalho com adição e subtração, questões estas mais frequentes na Educação Infantil. Em síntese: é preciso fazer com que as crianças pensem.

\begin{abstract}
Torna-se necessário planejar o trabalho de sala de aula, objetivando orientar as ações da criança por meio de situações-problemas, de modo que ela possa desenvolver com significados próprios as operações lógicas envolvidas nas noções matemáticas abordadas no problema (LORENZATO, 2008, p. 57).
\end{abstract}

Corroborando a assertiva do autor, é preciso entender que temos de iniciar o trabalho com as noções matemáticas com as crianças por onde elas estão (conhecimentos prévios) e não por onde gostaríamos que estivessem, numa perspectiva conteudista. Embora abordamos neste trabalho apenas questões ligadas à números, é importante destacar que na Educação Infantil, a abordagem matemática envolve outros sensos, conforme destaca Lorenzato (2008, p. 24): "O espacial, das formas que apoiará os estudos da geometria, os números, das quantidades, que apoiará o estudo da aritmética, e o das medidas, que desempenhará a função de integrar a geometria com a aritmética". Além do tripé da aprendizagem matemática na infância, referenciado pelo autor, 
há na literatura especializada na temática indicações das possibilidades de experiências, nas vivências das professoras com as crianças, que incorporem a estatística e probabilidade (LOPES, 2003).

Por fim, a partir das considerações apresentadas, pode-se afirmar que é importante que os professores proponham situações envolvendo números, geometria, medidas, estatística e probabilidade de modo a conhecer qual a apropriação das crianças acerca da natureza dessas noções, ou seja, por meio de tarefas que incorporem o aspecto lúdico, em interações e brincadeiras, de forma que a relação adulto-criança transcorra de acordo com os pressupostos das Diretrizes Curriculares Nacionais para a Educação Infantil - DCNEI's - (BRASIL, 2010), ao se demarcar, no currículo da infância, conjunto amplo de práticas pedagógicas que contribua ao desenvolvimento infantil de forma integral com acesso às múltiplas linguagens de meninos e meninas, nas mais diversas áreas do conhecimento humano (BRASIL, 2010).

\section{Percurso metodológico}

O estudo descrito neste artigo resulta de uma pesquisa qualitativa, de natureza descritiva, que teve como base perceber algumas características da presença da Matemática no cotidiano da Educação Infantil, especificamente em relação à abordagem de noções numéricas.

A pesquisa qualitativa encontra-se em variados tipos de investigação, apoiadas em diferentes quadros de orientação teórica e metodológica. Godoy (1995, p. 21) considera que "[...] a abordagem qualitativa, enquanto exercício de pesquisa, não se apresenta como uma proposta rigidamente estruturada, ela permite que a imaginação e a criatividade levem os investigadores a propor trabalhos que explorem novos enfoques".

Para a operacionalização e desenvolvimento do trabalho de campo, no sentido de tentar atingir os objetivos propostos, recorremos a observações decorrentes tanto de práticas de estágio obrigatório no decorrer da formação inicial da segunda autora, durante o ano de 2015, quanto de uma amostra, no ano de 2016, em que se selecionou duas professoras de jardim de infância para observação esporádica de suas práticas, em um Centro Integrado de Educação Infantil do município de Naviraí, interior do Estado de Mato Grosso do Sul (MS).

De modo geral, objetivou-se identificar o que professoras ensinam sobre números para crianças da pré-escola na perspectiva de compreensão de como essa área é abordada. Na tentativa de responder o foco investigativo, o trabalho de campo deu-se a partir dos objetivos específicos relacionados no quadro abaixo: 
Quadro 2: Relação entre objetivos específicos e indicadores de pesquisa.

\begin{tabular}{|c|c|}
\hline OBJETIVOS & INDICADORES \\
\hline $\begin{array}{l}\text { - Conhecer as práticas das } \\
\text { professoras da Educação Infantil } \\
\text { na inserção dos números como } \\
\text { conteúdo matemático; }\end{array}$ & $\begin{array}{l}\text { - Importância atribuída aos } \\
\text { números na Educação infantil; } \\
\text { - } \text { Forma de seleção dos conteúdos; } \\
\text { - Desenvolvimento dos conteúdos } \\
\text { durante as aulas; } \\
\text { - Orientação pedagógica para o } \\
\text { trabalho com o conteúdo. }\end{array}$ \\
\hline $\begin{array}{l}\text { - Analisar a forma como esse } \\
\text { conteúdo é trabalhado com as } \\
\text { crianças no sentido de descrever } \\
\text { as abordagens metodológicas } \\
\text { adotadas; }\end{array}$ & $\begin{array}{l}\text { - Metodologia utilizada (materiais } \\
\text { e recursos); } \\
\text { - Interação professora/crianças na } \\
\text { compreensão dos conteúdos; } \\
\text { - Forma de abordagem do } \\
\text { conteúdo. }\end{array}$ \\
\hline $\begin{array}{l}\text { - Caracterizar os fundamentos } \\
\text { e materiais recorridos pelas } \\
\text { professoras para o trabalho com } \\
\text { números. }\end{array}$ & $\begin{array}{l}\text { - Planejamento pedagógico das } \\
\text { professoras declarado em suas } \\
\text { afirmações; } \\
\text { - Elementos que fundamentam a } \\
\text { prática das professoras. }\end{array}$ \\
\hline
\end{tabular}

Fonte: Os autores, 2016.

Conforme demonstra o quadro, os indicadores de pesquisa, elaborados para a análise de dados, serviram de orientação para as discussões emergentes do processo investigativo, haja vista que, durante as observações, conseguimos catalogar recursos e tipos de materiais recorridos pelas docentes para a abordagem numérica.

Os indicadores serviram para amparar e subsidiar tanto as observações nas turmas com as professoras (no estágio e na exploração) quanto para direcionar a análise dos dados de uma forma geral.

Tendo em vista a delimitação dos objetivos e a elaboração dos indicadores, fomos a campo a partir de duas etapas:

1a) As observações no âmbito da Educação Infantil: Nesta etapa, tivemos a oportunidade de, desde o estágio realizado em 2015 (primeiro e segundo semestre), observar atentamente a rotina de turmas de creche e pré-escola em diferentes instituições de educação para a infância no município em questão.

Já neste período, fomos catalogando, por meio de relatórios e anotações no diário de campo, o modo como as docentes enfocavam os números 
com as crianças. Verificamos uma prática instrumental em que, por meio da rotina diária, a contagem oral do número de meninas e meninos presentes no dia, como também a leitura dos numerais, eram mais recorrentes, sem um trabalho mais sistematizado.

A partir dessa realidade, em 2016, fomos a campo, com um estudo mais exploratório, no sentido de acompanhar duas professoras da pré-escola, em momentos esporádicos. Isso foi importante para confirmação de algumas hipóteses que tínhamos inicialmente, bem como para entender algumas concepções que regem o trabalho pedagógico com a Matemática na Educação Infantil.

A técnica de observação, enquanto recurso para coleta de dados, é um importante elemento para a pesquisa educacional. Ela constitui um dos principais instrumentos de recolha de informações nas abordagens qualitativas, pois:

\begin{abstract}
A experiência direta é o melhor teste de verificação da ocorrência de um determinado assunto. O observador pode recorrer aos conhecimentos e experiências pessoais como complemento no processo de compreensão e interpretação do fenômeno estudado. A observação permite também que o observador chegue mais perto da perspectiva dos sujeitos e se revela de extrema utilidade na descoberta de aspectos novos de um problema. Por último, a observação permite a coleta de dados em situações em que é impossível estabelecer outras formas de levantamento ou outras formas de comunicação (LUDKE; ANDRÉ, 1986, p. 45).
\end{abstract}

Em concordância com as autoras, vimos a importância de ser ter esse contato direto com o cenário natural do objeto de estudos: a sala de aula. Isso para que pudéssemos ter subsídios sobre como as professoras organizam e desenvolvem atividades relacionadas ao tema pesquisado.

2a) A entrevista semiestruturada: Aqui tivemos, ao final das observações, um momento de reflexão junto às docentes atuantes na pré-escola sobre algumas questões ligadas às observações de suas práticas a partir de um roteiro de entrevista que possibilitou tentar compreender dados para além do que observamos.

As perguntas que compuseram o roteiro foram estruturadas de forma que possibilitassem perceber questões ligadas a: formação acadêmica das professoras, as noções matemáticas que consideravam importante trabalhar na Educação Infantil, o desenvolvimento do conceito de número, como também sobre a sua atuação profissional. 
Quadro 3: Dados de caracterização das professoras participantes da pesquisa.

\begin{tabular}{|c|c|c|c|c|c|}
\hline & IDADE & $\begin{array}{c}\text { FORMAÇÃO } \\
\text { INICIAL } \\
\text { (ANO) }\end{array}$ & $\begin{array}{c}\text { PÓS- } \\
\text { GRADUAÇÃO }\end{array}$ & $\begin{array}{c}\text { TEMPO DE } \\
\text { ATUAÇÃO } \\
\text { NA } \\
\text { DOCÊNCIA }\end{array}$ & $\begin{array}{c}\text { TEMPO DE } \\
\text { ATUAÇÃO } \\
\text { NA } \\
\text { EDUCAÇÃO } \\
\text { INFANTIL }\end{array}$ \\
\hline PROFA. 1 & 36 & $\begin{array}{c}\text { Pedagogia } \\
\text { (2012) }\end{array}$ & $\begin{array}{c}\text { Neuropedagogia } \\
\text { e Educação } \\
\text { Infantil e Séries } \\
\text { Iniciais }\end{array}$ & 2 anos & 2 anos \\
\hline PROFA. 2 & 33 & $\begin{array}{c}\text { Normal } \\
\text { Superior e } \\
\text { Pedagogia } \\
\text { (2006) }\end{array}$ & $\begin{array}{c}\text { Educação } \\
\text { Infantil, Séries } \\
\text { iniciais e Artes }\end{array}$ & 9 anos & 9 anos \\
\hline
\end{tabular}

Fonte: Os autores, 2016.

Conforme dados do quadro 3, as professoras entrevistadas têm formação em Pedagogia e pós-graduação na área, sendo uma ainda em fase de iniciação profissional (PROFA. 1) e a outra em pleno desenvolvimento na carreira (PROFA. 2).

Por fim, após termos o processo de coleta de dados finalizado, tentamos com base na observação e entrevista atender os objetivos inicialmente traçados.

\section{Da contagem oral à adição: a rotina do trabalho pedagógico}

Como já declarado anteriormente, o trabalho das observações nas turmas da Educação Infantil deu-se no contexto do estágio obrigatório durante a formação inicial de professores em um curso de Pedagogia, do qual fomos integrantes (professor e acadêmica). Desse modo, o período mencionado abarcou momentos desde o berçário I (bebês de quatro meses) até à pré-escola (crianças de 5 anos), no sentido de conhecer/vivenciar as práticas das professoras e compreender como cada atividade relacionada a números era trabalhada.

No berçário I foi perceptível que as professoras tiveram uma preocupação em organizar o espaço para a recepção das crianças. A maioria das atividades propostas no período observado estiveram relacionadas ao movimento, à música e à oralidade, trabalhando noções matemáticas como, por exemplo, a exploração do espaço por meio de deslocamentos dos bebês, mesmo que 
não intencionalmente, mas isso fora feito, como também atividades utilizando caixas de vários tamanhos. Houve vezes que bolas eram utilizadas para perceber noções de "dentro" e "fora" da caixa em brincadeiras.

Notamos a falta de articulação entre a maioria das tarefas matemáticas propostas, pois não se identificou uma especificidade tanto da professora quanto da natureza do que era proposto. Trabalhar Matemática com bebês não é uma tarefa fácil, contudo, outras noções podem favorecer o desenvolvimento do senso numérico, desde que estimulada a capacidade de pensar e resolver problemas nas primeiras vivências infantis.

Uma atividade que chamou a atenção foi quando a professora trouxe para a sala instrumentos musicais. A docente mostrava para os bebês os materiais e colocava em um lugar um pouco distante de onde estavam sentados, isso propositalmente, para que os mesmos não alcançassem. Então, os bebês tinham que engatinhar e pegar o instrumento que mais tivessem chamado a sua atenção a partir das propriedades físicas do objeto.

Nesta proposta, de natureza matemática, há implicitamente a ideia de comparação, princípio necessário para o desenvolvimento do número, uma vez que este constitui um procedimento mental básico em que o sujeito precisa estabelecer diferenças e semelhanças entre dois ou mais elementos (LORENZATO, 2008). Além disso, ao comparar os objetos, o bebê terá de tomar uma decisão, ou seja, resolver uma situação-problema.

De acordo com o RCNEI (BRASIL, 1998, p. 212), ao organizar referenciais para a prática de ensino, considera que ao trabalhar conhecimentos matemáticos "[...] por meio da resolução de problemas, as crianças estarão, consequentemente, desenvolvendo sua capacidade de generalizar, analisar, sintetizar, inferir, formular hipótese, deduzir, refletir e argumentar".

Nesse sentido, as crianças, para alcançarem o seu brinquedo, tinham que analisar o caminho a percorrer, sistematizar a melhor forma de alcançá-lo, formular a hipótese antes mesmo de sair do lugar, deduzir, refletir sobre o seu trajeto e, por fim, chegar ao seu destino com êxito.

Ao pensar nos objetivos deste trabalho de pesquisa, cumpre salientar que, como esclarece Kamii (2012, p. 18), a “[...] criança não constrói o número fora do contexto geral do pensamento no dia a dia", ou seja, para estabelecer relações numéricas, o sujeito precisa, necessariamente, pensar. Ao agir a criança pensa, ao pensar ela está estabelecendo relações mentais sobre o objeto, haja vista a importância da articulação entre a abstração física e reflexiva durante a construção do conceito de número.

Num segundo momento, ainda em 2015, pudemos observar no 
berçário II uma dificuldade imensa das professoras em organizar tarefas com as crianças. Tais dificuldades, quando analisadas pelo contexto, pareciam residir na fata de articulação entre o binômio cuidar/educar na creche. Assim, concluímos neste período que não houve, ao menos nos dias observados no estágio, práticas relacionadas tanto à Matemática quanto a outras áreas do conhecimento, ficando em predominância a utilização da televisão e do rádio, como forma de passatempo no ambiente.

Nessa fase, não foram observadas a presença de vivências relacionadas ao conhecimento matemático, o que despertou em nós (professor orientador e acadêmica de Pedagogia), a relevância de explorar algumas atividades com as crianças, pois é preciso vivenciar momentos de aprendizagem com estas noções desde a mais tenra idade.

Num terceiro momento, já no maternal (crianças de 2 e 3 anos), pudemos perceber uma diferença enorme de uma turma a outra, uma vez que a professora explorava os campos matemáticos em diferentes momentos da rotina, desde a recepção ao lanche. Durante esse período, trabalhou autonomia, equilíbrio, coordenação motora, raciocínio lógico, geometria e muitas outras possibilidades observáveis na prática diária do grupo.

Numa destas atividades, foi perceptível a importância atribuída à construção de relações lógicas, já que a docente trouxe uma folha de papelão com desenhos de formas geométricas (círculo, quadrado, triângulo e retângulo) que apresentavam o traçado das figuras; além disso, disponibilizou, também em papelão, as formas representadas por peças soltas para que as crianças pudessem relacionar colando a figura no espaço destinado.

Pela exploração e envolvimento do grupo, foi possível verificar que a atividade em questão, aparentemente, foi de grande importância, haja vista que, nesta exploração, algumas relações mentais foram criadas com base no raciocínio lógico-matemático. Kamii $(2012$, p.18) considera que a aprendizagem da criança "[...] progride na construção do conhecimento lógico-matemático pela coordenação das relações simples que anteriormente ela criou entre os objetos", pressuposto este observável nesta proposta realizada com o maternal.

Em síntese geral destas observações, possibilitadas pelo estágio, foi nítida a identificação da necessidade de trabalhar a Matemática desde a Educação Infantil, no sentido de oportunizar às crianças momentos de recriação de suas experiências por meio de práticas que viabilizem a construção do raciocínio matemático, o que só é possível se o docente tiver um conhecimento sobre as propriedades matemáticas e suas especificidades.

Verificamos, a partir dos dados apresentados, que a prática peda- 
gógica com os campos desta área ainda é pouco recorrente no cotidiano de turmas de creches e jardins de infância. A maior parte das atividades parecem recair no campo numérico e demonstram uma natureza fragilizada e pobre, em termos de desenvolvimento de propostas, que possibilitem o pensamento e autonomia infantil.

Por essa razão, em 2016, sentimos a necessidade de ir a campo com o objetivo de sintetizar como professoras da pré-escola (jardim II e jardim III) exploravam o número com as crianças. Especificamente nestas turmas, não muito diferente do espaço da creche, o que predominou nas práticas das professoras foi a exploração do número no sentido cardinal. Como ressalta Lorenzato (2008, p. 38), o aspecto cardinal "[...] refere-se ao total de elementos que possui um (sub)conjunto e significa a relação de inclusão presente no conceito do número".

Nesse sentido, atividades de contagem oral do número de meninas e meninos presentes em cada dia, leitura coletiva dos numerais (sequência numérica) e a introdução à adição, quando do momento de perceber a quantidade total de crianças do dia, são propostas que ocorreram diariamente dentro da rotina das turmas de pré-escola. Para exploração destes aspectos, as professoras recorrem aos cartazes dispostos na sala e ao quadro (lousa) para sistematização e estruturação do algoritmo da adição.

Sobre a sequência numérica, verificamos um equívoco conceitual, uma vez que a contagem no momento da leitura dos numerais inicia-se pelo " 0 " (zero). Observamos que esta é uma prática habitual recorrida pelas professoras da Educação Infantil em que, muitas vezes, optam por trabalhar dessa forma porque consideram o número zero igual a outro qualquer ou, até mesmo, por reproduzirem em suas explicações orais que o zero é sinônimo de "nada", o que pode gerar uma má interpretação do papel deste número na contagem, pois o real significado dele é "ausência de unidade". "Se o zero não vale nada, por que na conta de vezes ele anula tudo?", "Se o zero não vale nada, por que 205 é diferente de 25?", "Se zero não vale nada, como ele tem para emprestar? " (LORENZATO, 2008, p. 35-36).

Nesta perspectiva de trabalho pedagógico com esta área do conhecimento, a relação número e quantidade presente nos cartazes naturalmente dispostos e explorados nos espaços das instituições de educação para a infância, parecem caminhar no sentido contrário à contagem, uma vez que, como vimos, é apresentada a ordem hierárquica de forma inadequada, quando a docente conta oralmente a partir do "0" (zero).

Lorenzato (2008), ao discutir o número e suas funções, acrescenta 
considerações importantes para o papel do zero na representação numérica que este ocupa. Segundo o autor, independente da concepção que o docente tenha sobre o zero, seu ensino merece considerações. Seguindo essa linha de pensamento, a atividade diária de leitura dos numerais na Educação Infantil merece atenção por parte dos professores, bem como o processo de contagem oral e a escrita dos números naturais. Assim, é preciso desmitificar práticas de contagem que se iniciam pelo zero, pelas razões apresentadas. Essas práticas, dissociadas de uma explicação conceitual, do ponto de vista da Matemática e de suas propriedades, podem gerar dificuldades na compreensão do sistema de numeração decimal em outros momentos da formação, haja vista que alguns obstáculos da aprendizagem parecem se situar no plano das relações entre conceituação e representação.

Cumpre salientar que o zero tem um papel importante e a forma mais adequada de se apresentá-lo, de acordo com Lorenzato (2008), é como sendo um número que tem a função de guardar lugar para os outros números.

Nesse entendimento, podemos inferir que um momento importante para desmitificar o valor do zero é a escrita do dez, pois "[...] ao escrever o dez, pela primeira vez para a criança o zero aparece como uma nova função: ele não anula e vale muito, tanto é que, sem ele, o número 1 vale uma unidade e, com ele, vale uma dezena, isto é, nove a mais" (LORENZATO, 2008, p. 36).

Portanto, este número, em uma prática pedagógica que vise a aprendizagem mais significativa, deveria ser o último número a ser ensinado, em situações diversificadas nas quais, por exemplo, faltem elementos a se contar ou em que seja preciso comunicar quantidades ausentes (ausência de unidade), em casos de jogos de marcação de pontuação em que os participantes necessitam registrar a falta de pontuação de um grupo.

Outro fator a ser tratado sobre a observação sistematizada nos quadros 4 e 5, diz respeito às professoras limitarem-se à leitura dos numerais até o "10" (dez) diariamente com base na exploração de cartazes contendo sequência numérica. Na nossa interpretação, tal tarefa de leitura apresenta-se um pouco contraditória quando a comparamos com a atividade diária de contagem oral do número de meninas e meninos presentes no dia, uma vez que as crianças contam, na segunda proposta, quantidades para além do "10" (dez) e isso não é trabalhado com o grupo. O que queremos dizer é que, ensina-se até o numeral dez, mas explora-se em diversas situações quantidades maiores sem discutir e ampliar o repertório numérico das crianças.

Com isso, podemos concluir que essa lógica de ensino parece ser contraditória nas relações e hipóteses que as crianças criam, socialmente, com 
o campo numérico. Conforme esclarece Teixeira et al. (2000, p.153):

\begin{abstract}
A criança constrói diferentes formas de representação a partir de situações vivenciadas por ela, na sala de aula e ou fora dela. No geral a proposta de trabalho com numeração na sala de aula se faz com base num conjunto de tarefas (agrupar e reagrupar objetos, codificar, decodificar) que visam a compreensão das regras dos agrupamentos e sua relação com o valor posicional do número.
\end{abstract}

A partir deste entendimento, fica perceptível a relevância do professor que ensina Matemática na Educação Infantil abordar as diferentes faces do número com as crianças, haja vista que elas, fora do ambiente escolar, vivenciam situações que envolvem comparação entre quantidades, questões referentes ao número de algarismos presentes numa escrita numérica, como também aspectos referentes à influência da numeração oral e escrita (LERNER; SADOVSKY, 1996).

Em síntese, a fragilidade desta abordagem, desde a creche, evidencia a falta de especificidade da formação para o ensino dos conteúdos matemáticos, pois tal realidade vem se apresentando como sendo "[...] um grande problema, tanto para crianças quanto para os professores que estão sendo formados nos cursos de Pedagogia" (GOMES 2002, p. 64). Além disso, outro fator que contribui para esse dado ainda parece residir na "cobrança" por parte dos pais que querem ver seus filhos (crianças) aprendendo as "continhas", como advoga Lorenzato (2008).

\title{
Para além do observável: o que dizem as professoras sobre o ensino de números
}

No caso específico da Matemática, reportando a essas dificuldades na organização da prática, entendemos que as teorias de aprendizagem e ensino de números poderiam auxiliar os docentes a identificarem suas limitações e perspectivas futuras em relação aos aspectos necessários à abordagem do campo numérico.

Quando analisamos o discurso das professoras de jardim de infância, é possível identificar que, ao menos na teoria, conseguem reconhecer pontos que não o fazem em suas práticas, como descrito no quadro abaixo: 
Quadro 4: Indicadores de pesquisa relacionados com os dados da entrevista.

\begin{tabular}{|c|c|c|}
\hline \multirow{2}{*}{ INDICADORES } & \multicolumn{2}{|c|}{ DADOS DA PESQUISA } \\
\hline & PROFA. 1 & PROFA. 2 \\
\hline $\begin{array}{l}\text { - Importância } \\
\text { atribuída aos } \\
\text { números na } \\
\text { Educação Infantil. }\end{array}$ & $\begin{array}{l}\text { "Com certeza é } \\
\text { importante né, porque } \\
\text { desde pequenas que } \\
\text { elas já se preparam, } \\
\text { já para a Matemática } \\
\text { é como eu falei né, [...] } \\
\text { a gente usa os dias } \\
\text { né". }\end{array}$ & $\begin{array}{l}\text { - } \text { "Aatemática } \\
\text { está voltada à vida } \\
\text { inteira das crianças } \\
\text { [...] a gente tem } \\
\text { que trabalhar } \\
\text { números desde } \\
\text { os pequenininhos } \\
\text { também, até na } \\
\text { creche". }\end{array}$ \\
\hline $\begin{array}{l}\text { - Forma de seleção } \\
\text { dos conteúdos. }\end{array}$ & $\begin{array}{l}\text { - "[...] eu quando vou } \\
\text { planejar, eu procuro, } \\
\text { assim, tudo que } \\
\text { envolva, que vai } \\
\text { trazer conhecimento } \\
\text { dos números porque } \\
\text { tanto a Matemática } \\
\text { tem essa importância } \\
\text { quanto outra } \\
\text { disciplina [...]". }\end{array}$ & $\begin{array}{l}\text { - "[...] A gente vai } \\
\text { tendo uma base de } \\
\text { como que a criança } \\
\text { está na Matemática } \\
\text { né. Todo dia fazendo } \\
\text { a contagem das } \\
\text { crianças [...]". }\end{array}$ \\
\hline $\begin{array}{l}\text { Desenvolvimento } \\
\text { das conteúdos } \\
\text { durante as aulas. }\end{array}$ & $\begin{array}{l}\text { "Então, eu trabalho } \\
\text { Matemática mais de } \\
\text { forma lúdica mesmo } \\
\text { até pela idade deles } \\
\text { né, [...]". }\end{array}$ & $\begin{array}{l}\text { - "Matemática eu } \\
\text { faço a rotina na sala } \\
\text { [...] faço a contagem } \\
\text { de quantos alunos } \\
\text { vieram [...] dessa } \\
\text { forma que a gente } \\
\text { vai fazendo". }\end{array}$ \\
\hline $\begin{array}{l}\text { Metodologia } \\
\text { utilizada } \\
\text { (materiais e } \\
\text { recursos). }\end{array}$ & $\begin{array}{l}\text { "Os meus alunos } \\
\text { na verdade [...] não } \\
\text { tinham muita noção } \\
\text { né de números, } \\
\text { de conceitos [...], } \\
\text { então eu trabalhei } \\
\text { através da realidade } \\
\text { deles, conforme as } \\
\text { dificuldades deles. } \\
\text { Que nem eu uso } \\
\text { bastante tampinhas, } \\
\text { palitos de sorvetes, } \\
\text { mas é também } \\
\text { através da rotina [...]". }\end{array}$ & $\begin{array}{l}\text { - "[... introduz na } \\
\text { rotina, e todos os } \\
\text { dias trabalhar com } \\
\text { os telefones, número } \\
\text { de casa, a idade } \\
\text { deles, qual mês que } \\
\text { faz aniversário [...] o } \\
\text { número hoje envolve } \\
\text { tudo né?! Telefone, } \\
\text { casa. Envolve tudo } \\
\text { na vida deles, eles } \\
\text { têm que estar ciente } \\
\text { disso também". }\end{array}$ \\
\hline
\end{tabular}




\begin{tabular}{|c|c|c|}
\hline $\begin{array}{l}\text { - Forma de } \\
\text { abordagem do } \\
\text { conteúdo. }\end{array}$ & $\begin{array}{l}\text { - "[...] fazendo } \\
\text { dinâmicas que usam } \\
\text { os números, mais (...) } \\
\text { mais forma lúdica } \\
\text { mesmo". }\end{array}$ & $\begin{array}{l}\text { - "Então, a gente } \\
\text { divide a sala com as } \\
\text { crianças meninos e } \\
\text { meninas, aí vamos } \\
\text { fazer a contagem } \\
\text { de quantos } \\
\text { meninos vieram, } \\
\text { [...] assim, a gente } \\
\text { vai introduzindo a } \\
\text { Matemática". }\end{array}$ \\
\hline $\begin{array}{l}\text { Planejamento } \\
\text { pedagógico das } \\
\text { professoras. }\end{array}$ & $\begin{array}{l}\text { - "[...] eu faço o } \\
\text { planejamento de } \\
\text { acordo com as aulas, } \\
\text { como eu posso te } \\
\text { dizer, mais com } \\
\text { brincadeira assim } \\
\text { mesmo, sabe?" }\end{array}$ & $\begin{array}{l}\text { - "...] a gente vai } \\
\text { tendo uma base de } \\
\text { como que a criança } \\
\text { está na Matemática } \\
\text { né?! Todo dia } \\
\text { fazendo a contagem } \\
\text { das crianças, e a } \\
\text { gente vai reproduzir } \\
\text { uma atividade } \\
\text { xerocopiada [...]". }\end{array}$ \\
\hline $\begin{array}{l}\text { Elementos que } \\
\text { fundamentam } \\
\text { a prática das } \\
\text { professoras. }\end{array}$ & $\begin{array}{l}\text { - "[...] a importância } \\
\text { dos números, [...] o } \\
\text { zero o primeiro no } \\
\text { caso, que vem antes } \\
\text { do um, depois o dois } \\
\text { em uma sequência e } \\
\text { para isso a gente tem } \\
\text { os cartazes que ajuda } \\
\text { bastante ali também, } \\
\text { eles aprenderem } \\
\text { né?! Que eles têm a } \\
\text { sequência e o lugar } \\
\text { deles [...]". }\end{array}$ & $\begin{array}{l}\text { - "[...] eu faço a rotina } \\
\text { na sala, com tempo, } \\
\text { com os horários, } \\
\text { com quem vai ser } \\
\text { as professoras que } \\
\text { vão entrar, faço a } \\
\text { contagem de quantos } \\
\text { alunos vieram, [...] } \\
\text { e dessa forma que a } \\
\text { gente vai fazendo". }\end{array}$ \\
\hline
\end{tabular}

FONTE: Os autores, 2016.

A partir das informações declaradas em entrevistas, a importância atribuída aos números na Educação Infantil reside, nos dois casos, no fato de a Matemática estar presente na vida das crianças desde pequenas, como destacam as docentes.

Além disso, ao que tudo indica, parece haver ainda uma crença de que o campo matemático se restringe ao ensino apenas de número, com base em duas questões: ordem e a inclusão hierárquica, procedimentos estes já apontados por Kamii (2012). Mas, quando confrontamos isso com as recomendações da literatura especializada sobre a temática, percebemos ser preciso 
fazer uma opção metodológica de trabalho que aborde outros aspectos com as crianças, uma vez que o uso social do número vem sendo cada vez mais frequente em práticas de letramento no âmbito da Matemática, ou seja, o professor precisava adotar uma vertente pedagógica que oportunize o acesso às propriedades matemáticas em uma ampla relação com as experiências infantis fora da escola.

Em relação à seleção dos conteúdos do bloco "números e sistema de numeração", em ambos os casos, a prática comum foi a de trabalhar números com base na utilização diária do mesmo, ou seja, as docentes consideraram necessária a abordagem de procedimentos que envolvessem ações do dia a dia das crianças como, por exemplo, contagem oral, sequência número e a relação número/quantidade.

Sobre o ensino de número, por meio de pesquisas piagetianas, Kamii (2012, p. 17) nos mostra que é preciso nesta abordagem estabelecer "[...] uma distinção fundamental entre três tipos de conhecimentos básicos e seu modo de estruturação: conhecimento físico, conhecimento lógico-matemático e conhecimento social".

Partindo desse viés, como podemos relacionar no quadro 6, ao questionarmos as professoras sobre como abordam números para as crianças, em resposta obtivemos declarações pautadas em momentos de brincadeiras, como também em ações da divisão do número de crianças presentes cada dia, com respectiva sistematização do algoritmo da adição no quadro (lousa).

Os dados observados e as informações declaradas pelas docentes recaem na perspectiva de ensino clássico de números, em que a abordagem reside nas explicações dadas pelo professor em um discurso pautado em sua figura como sendo o detentor do saber matemático.

Em concordância com Kamii (2012), reafirmamos que este ensino vem sendo realizado a partir do conhecimento social e não do conhecimento lógico-matemático (representações mentais do indivíduo). Ainda segundo a autora, "[...] as pessoas que acreditam que os conceitos numéricos devem ser ensinados através da transmissão falham por não fazerem a distinção fundamental entre o conhecimento social e o lógico matemático, a base fundamental do conhecimento é a própria criança [...]" (KAMII, 2012, p. 26).

Então, concluímos aqui que, para se introduzir uma noção matemática, a professora deveria fazer com que as crianças pensassem e coordenassem suas relações mentais a partir do conhecimento lógico-matemático das mesmas, relacionando-o com o conhecimento social, uma vez que número é uma relação mental feita por cada indivíduo. Nessa perspectiva, o professor não 
ensina número, ele oportuniza situações para que este conceito seja construído e fundamentado pela criança que, na medida em que pensa sobre diversos tipos de relações, abstrai reflexivamente representações de quantidades.

O êxito do processo ensino-aprendizagem decorre, em alguns casos, da maneira como o professor organiza as suas atividades no cotidiano das instituições, ou seja, na forma como organiza o tempo e espaço na Educação Infantil.

$\mathrm{Na}$ tentativa de compreender melhor a realidade presente, questionamos as professoras sobre quais recursos utilizavam para trabalharem a temática números. As respostas fizeram referência, como evidenciado no quadro interpretativo, a alguns materiais manipuláveis ("concretos") semiestruturados (informais), por exemplo, palitos e tampinhas, como ainda o trabalho com jogos, brincadeiras e a exploração dos cartazes decorativos presentes nas paredes da sala.

Uma das ideias equivocadas na abordagem dos aspectos do ensino de números desde a Educação Infantil reside no enfoque clássico. Ensinar números, nestes moldes, passa necessariamente por uma organização em que se ensina primeiro o " 1 ", depois o "2", "3" e, assim, sucessivamente. Moreno (2006, p. 43-44) esclarece que nesta perspectiva metodológica, "[...] se afirma que se deve ensinar os números aos poucos, um a um e na ordem que a série numérica indica".

Tal percepção fica evidente nas falas das professoras do jardim de infância deste estudo, pois afirmam que "o zero, o primeiro no caso, que vem antes do um, depois o dois em uma sequência" (PROFA. 1). Como podemos ver, esse ensino dito como "clássico" ainda prevalece na pré-escola, fazendo com que as crianças não pensem no sentido de quantificarem, mas sim, que decorem uma sequência, não compreendendo o real significado do número.

Na prática, tanto da PROFA. 1 quanto da PROFA. 2, ficou claro que os aspectos abordados em relação aos números se restringiram à transmissão de rudimentos de escrita numérica, identificação e reconhecimento dos algarismos (0 ao 10), sequência numérica e contagem oral.

De forma mais adequada, como ressalta Kamii (2012, p.65), a “[...] criança não constrói o número fora do contexto geral do pensamento no dia-a-dia. Portanto, o professor deve encorajar a criança a colocar todos os tipos de coisas, ideias e eventos em relações todo o tempo, em vez de focalizar apenas a quantificação [...]", dado este muito recorrente nos aspectos abordados pelas professoras desta investigação.

Finalizando a resposta desta indagação, as recomendações da Educação Matemática na infância para a abordagem de números colocam ser 
importante que o professor aproveite momentos que envolvam: vida diária, distribuição de materiais, divisão de objetos, coleta de coisas, manutenção de quadros e registro, votação, jogos em grupo, jogos com alvos, jogos de esconder, corridas e brincadeiras de pegar, jogos de adivinhações, jogos de tabuleiro, jogos de baralho, entre outros (KAMII, 2012).

Em suma, acreditamos ser preciso um trabalho que aborde o número em suas diferentes facetas de acordo com o que menciona Lorenzato (2008), e os caminhos para tal pressuposto de trabalho são expostos por Kamii (2012), o que aponta para a necessidade do educador matemático da infância se aprimorar e ressignificar seu fazer docente por meio da aproximação da pesquisa sobre o ensino de Matemática.

\section{Considerações finais}

Esta investigação procurou conhecer práticas de professoras da Educação Infantil (jardim de infância) na inserção dos números como uma das noções matemáticas essenciais a ser desenvolvida com a criança pequena. A aproximação com o contexto estudado possibilitou perceber que a docência em Matemática na Educação Infantil vem apresentando dificuldade em associar o que se aprende sobre as recomendações para a abordagem numérica e o que ocorre na prática escolar. Muitas vezes, as professoras deixam de desenvolver tarefas ligadas ao número e suas diferentes facetas por não terem ciência de como fazer. Por essa razão, a rotina da instituição acaba sendo o ponto-chave do trabalho pedagógico, o que faz com que introduzam o conceito de número sob o enfoque de ensino clássico (apresentação dos números por meio da ordem sequencial).

Para que pudéssemos ter uma maior compreensão da situação estudada, os indicadores de pesquisa foram primordiais para a análise, pois serviram de orientação para discussões emergentes do processo investigativo, haja vista que, durante as observações, conseguimos catalogar recursos e tipos de materiais recorridos pelas docentes, sendo os cartazes a prática mais recorrente. Nesse sentido, em cada indicador relacionamos as falas das professoras compreendendo assim, com mais especificidade, o que elas entendem e trabalham sobre números com as crianças.

Os dados analisados, a partir das observações e das entrevistas, permitiram a identificação de alguns limites e perspectivas futuras que marcaram uma agenda de pesquisa e de estudos futuros, dentre elas, a mais marcante refere-se ao significado do "0" para as professoras e sua forma de introdução 
com as turmas, questão esta que merece ser explorada em investigações futuras sobre a temática.

Os resultados finais indicam que prevalece, desde a pré-escola, a crença de que a exploração do número precisa, fundamentalmente, restringir-se apenas ao aspecto cardinal do mesmo, o que vai na contramão das experiências infantis e do uso social deste campo tão relevante para a formação do pensamento matemático na infância. Além disso, pela observação, vimos ainda que a apresentação dos números se restringiu também até o "10", o que nos faz questionar: o que vem depois do "10"? As experiências e vivências, características da faixa etária de crianças em idade pré-escolar, nos levam a crer que as hipóteses são inúmeras, desde que o docente consiga dar abertura à participação ativa nas tarefas que coloca em destaque com o grupo que atua.

\section{Referências}

BRASIL, Ministério da Educação. Secretaria de Educação Básica. Referencial Curricular Nacional para a Educação Infantil. Vol. 3. Conhecimento de Mundo. Secretaria de Educação Básica. SED-MEC, 1998. Disponível em: http:// portal.mec.gov.br/seb/arquivos/pdf/volume3.pdf. Acesso em: 15 abr. 2017.

BRASIL, Ministério da Educação. Secretaria de Educação Básica. Diretrizes Curriculares Nacionais para a Educação Infantil. Brasília: MEC, SEB. 2010. Disponível em: https://ndi.ufsc.br/files/2012/02/Diretrizes-Curriculares-para-a-E-I.pdf. Acesso em: 20 abr. 2017.

GODOY, A. S. Introdução à pesquisa qualitativa e suas possibilidades. $R A E$ Revista de Administração de Empresas, São Paulo, v. 35, n. 2, p. 57-63, 1995. Disponível em: http://www.scielo.br/pdf/rae/v35n2/a08v35n2.pdf. Acesso em: 15, mai. 2017.

GOMES, M. G. Obstáculos epistemológicos, obstáculos didáticos e o conhecimento Matemático nos cursos de formação de Professores das séries iniciais no Ensino Fundamental. Contrapontos - ano 2 - n. 6 - p. 423-437 - Itajaí, set./ dez. 2002. Disponível em: https://siaiap32.univali.br/seer/index.php/rc/article/view/181/153. Acesso em: 20 jan. 2017.

KAMII, C. A criança e o número: implicações educacionais da teoria de Piaget para a atuação com escolares de 4 a 6 anos. $39^{\circ}$ ed.Campinas, SP: Papirus. 2012.

LERNER, D.; SADOVSKY, P. O sistema de numeração: um problema didático. In: PARRA, C.; SAIZ, I. (orgs.). Didática da Matemática: reflexões psicopedagógi- 
cas. Porto Alegre. Artes Médicas, 1996.

LOPES, C. A. E. O conhecimento profissional dos professores e suas relações com estatística e probabilidade na Educação Infantil. 2003. 290f. Tese (Doutorado em Educação) - Faculdade de Educação da Universidade Estadual de Campinas - FE/UNICAMP, Campinas-SP. 2003. Disponível em: http://repositorio.unicamp.br/jspui/bitstream/REPOSIP/253899/1/Lopes_CeliAparecidaEspasandin_D.pdf. Acesso em: 20 jun. 2018.

LORENZATO, S. Educação Infantil e a percepção da matemática. $2^{\circ}$. ed. rev. ampliada - Campinas. SP: Autores associados, 2008.

LUDKE, M.; ANDRÉ, M. E. D. Pesquisa em educação: abordagens qualitativas. São Paulo, Editora Pedagógica e Universitária, 1986.

MINAYO, M. C. S. O desafio do conhecimento. São Paulo: Hucitec,1993

MORENO, B. R. O ensino do número e do sistema de numeração na educação infantil e na primeira série. In: PANIZZA, M. Ensinar matemática na educação infantil e nas séries iniciais: análises e propostas. Porto alegre. 2006. p. 43-76.

MORETTI, V. D.; SOUZA, N. M. M. Educação matemática nos anos iniciais do ensino fundamental: princípios e práticas pedagógicas. $1^{\circ}$ ed. São Paulo: Cortez, 2015.

TEIXEIRA, L. R. M.; LIMA, C. M.; CARLOS, D. F.; PETERSON, J.; CAVALI, R. As representações simbólicas e os significados construídos por alunos do ensino fundamental sobre a escrita numérica. Nuances. Presidente Prudente, SP. 2000. Vol. VI. p. 143-155. Disponível em: http://revista.fct.unesp.br/index. php/Nuances/article/view/125/163. Acesso em: 30 jan. 2017.

Data de recebimento: 28.10 .2019

Data de aceite: 02.05.2020 